\title{
AC 2007-3050: INCREASING ENROLLMENT OF MINORITY WOMEN IN ENGINEERING
}

\section{Showkat Chowdhury, Alabama A\&M University}

Dr. Showkat Chowdhury is an Associate Professor in the Department of Mechanical Engineering at Alabama A\&M University in Huntsville, AL. Dr. Chowdhury has extensive background in teaching undergraduate and graduate students in Mechanical Engineering, and performing research in the fields of Computational Fluid Dynamics, Combustion, Propulsion, Heat \& Mass Transfer and Turbulence. Previously, he worked as a Professor at Bangladesh University of Engineering \& Technology (BUET) and at University of Brighton, U.K. He also worked in the Research Division of Corning Inc. He earned his Ph.D. and M.S. in Mechanical Engineering from Clarkson University, New York and B.S. in Mechanical Engineering from BUET.

\section{Tamara Chowdhury, Alabama A\&M University}

Tamara Chowdhury is an Assistant Professor in the Department of Civil Engineering at Alabama A\&M University in Huntsville, AL. Mrs. Chowdhury has extensive background in teaching undergraduate students in the Department of Civil Engineering, and conducting research in mathematical modeling, flood map generation and environmental impact assessment using various softwares. She also worked for a multinational research organization for many years. Mrs. Chowdhury earned her MS in Civil engineering from Clarkson University, New York, USA and B.S. in Civil Engineering from Bangladesh University of Engineering \& Technology. 


\title{
Increasing Enrollment of Minority Women in Engineering
}

\begin{abstract}
The percentage of African American Engineers in the national workforce is very low. Among them, the percentage of Female African American Engineers is significantly lower, double minority, which generates a real concern and needs immediate attention.

This paper investigates the participation of women engineers, particularly minority black women engineers in various courses in the Department of Civil Engineering and Department of Mechanical Engineering at Alabama A\&M University. The female students were found to be only approximately $20 \%$ of the undergraduate engineering students. The average grades received by the male and female students in various undergraduate courses in both the Civil and Mechanical engineering departments were calculated for comparison. The women student average grades in most cases were better than their male counterpart, which demonstrates that they are capable of studying engineering along with the male students, if they choose so.
\end{abstract}

To explore the cause of low attendance of female students in engineering, as an assessment tool a survey instrument was developed, and was completed by women students of both the Civil and Mechanical engineering departments. The survey results were analyzed and data for both departments were compared. Based on the survey results various social aspects including general tendency of women to study liberal arts, misconception about engineering, lack of proper math and science courses in high school, etc were identified, which causes low participation of women in engineering.

In order to increase the enrollment and retention of women in engineering programs, a survey tool was also developed and completed by the undergraduate Civil and Mechanical Engineering students. The study shows that certain facilitating conditions including scholarship, summer internship, awareness generation about the benefits of engineering education, increased levels of self-confidence development, desire to study technical education, etc are required. This paper shows that by implementing certain pre-conditions, the enrollment of minority African American Women Engineers can be significantly increased which will lead to a balanced workforce and improve the national economy. 


\section{Background}

Alabama Agricultural and Mechanical University (AAMU), a historically black university, was founded in 1875. Alabama A\&M University reflects the uniqueness of the traditional landgrant institution combining teaching, research, service, liberal arts, and vocational fields. The university offers baccalaureate, masters and doctoral level degrees that are compatible with the times to all qualified and capable individuals who are interested in further developing their technical, scientific, professional, and scholastic skills and competencies. The university operates with the three-fold function of teaching, research, and extension and other public service. Alabama A\&M University, a center of excellence, provides an educational environment for the emergence of scholars, scientists, leaders, critical thinkers, and other contributors to a global society. AAMU is located in Huntsville, Alabama, which is known internationally as a center of aerospace and defense technology. Huntsville is considered as a leader in high-tech research, engineering services, information systems design and in the manufacturing of computing equipment, telecommunications, space vehicles and rocket propulsion, and attracts some of the greatest minds in the world. It is the home of more than 50 Fortune 500 companies. These industries and government agencies require a large number of qualified engineers.

Alabama A\&M University's School of Engineering and Technology offers three engineering programs, Civil Engineering, Electrical Engineering and Mechanical Engineering. The three engineering programs presently enroll over 500 undergraduate engineering students.

Civil Engineering (CE) includes the broad categories of construction, structural engineering, soil mechanics and foundations, transportation systems, water resources, hydraulic engineering, and environmental engineering. The Department of Civil Engineering at Alabama A\&M University provides a general academic background while allowing a student to concentrate on a specialized area by selecting technical electives. The Department offers a major leading to the Bachelor of Science in Civil Engineering and provides basic courses in all of the areas: Structural Analysis and Design, Geotechnical Engineering, Environmental Engineering and Water Resources, and Transportation Engineering.

The Mechanical Engineering (ME) program at Alabama A\&M University started in 1997, as a result of a desegregation lawsuit. The program encompasses the traditional roles of Mechanical Engineering in areas of analysis, design, manufacturing, and testing of mechanical and thermal systems, while also including system integration, propulsion systems, concurrent engineering, and other competitive manufacturing practices. Based on the local demand, the program has two options: Manufacturing and Propulsion. The Mechanical Engineering Department at AAMU is committed to prepare students in these options, to work efficiently for various industries and government.

Both the Mechanical and Civil Engineering programs at AAMU were successfully accredited by $\mathrm{ABET}^{1}$, the last one in Fall 2002. 


\section{Minority Female Engineers}

Developed countries like the United States need large engineering workforce. Even in Huntsville, the city where Alabama A\&M University is located, it is anticipated that over 12000 engineers will be needed between now and year 2012. But unfortunately, the percentage of minority black engineers is very low compared to the percentage of their population ${ }^{2,3}$. Among them, the percentage of female black engineers is even lower ${ }^{4,5}$. In order to have a better statistical data, the percentage of male and female students in a number of engineering courses in both the Civil Engineering and Mechanical Engineering departments at AAMU were calculated and presented in Fig. 1. In this figure, the horizontal axis denotes the course numbers for various Civil and Mechanical Engineering courses as described in Table 1, and the vertical axis denotes the percentage of male or female students for a particular course. From the figure it is found that the percentage of female engineering students is only about $20 \%$ of the class. As already mentioned, the number of minority black engineers in the national workforce is very low, and hence the number of female black engineers become alarming low, double minority.

For analyzing the capability of the female students in studying engineering, the average grades for both the male and female students in the said courses were calculated, and plotted in Fig. 2. Here, the horizontal axis shows the various course numbers, while the vertical axis shows the average grade point for male or female students in the class, for a particular course. From Fig. 2 , it is observed that average grades for female students are most of the time slightly better than the male students. This means that the female students are quite capable for studying engineering along with the male students, if they want to do so. Also, it was noted by the course instructors that the female students are normally more sincere, submit home-works timely, more concerned, and neat in their work.

Table 1. Course number and course title of various Civil Engineering and Mechanical Engineering courses.

\begin{tabular}{|l|l|}
\hline Course Number & Course Title \\
\hline EGC 101 & Engineering Drawing \& Graphics \\
\hline EGC 205 & Statics \\
\hline CE 305 & Hydrogeology \\
\hline CE 404 & Hydraulic Engineering and Design \\
\hline ME 101 & Intro to Mechanical Engineering \\
\hline ME 310 & Thermodynamics \\
\hline ME 312 & Heat \& Mass Transfer \\
\hline ME 411 & Power Plant Performance \\
\hline ME 413 & Rocket Propulsion \\
\hline
\end{tabular}




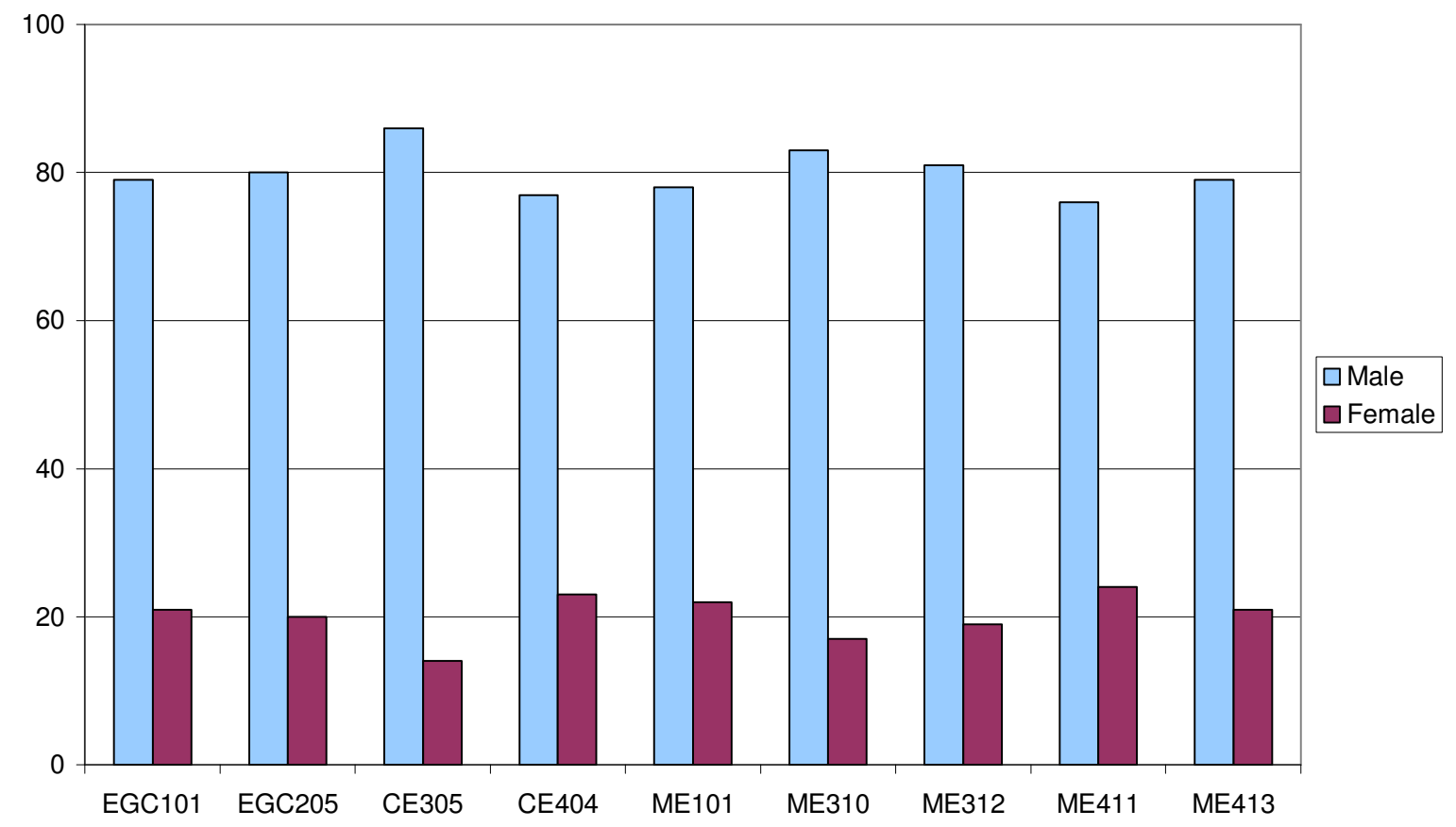

Fig. 1. Male and Female student percentage in different Civil and Mechanical Engineering courses.

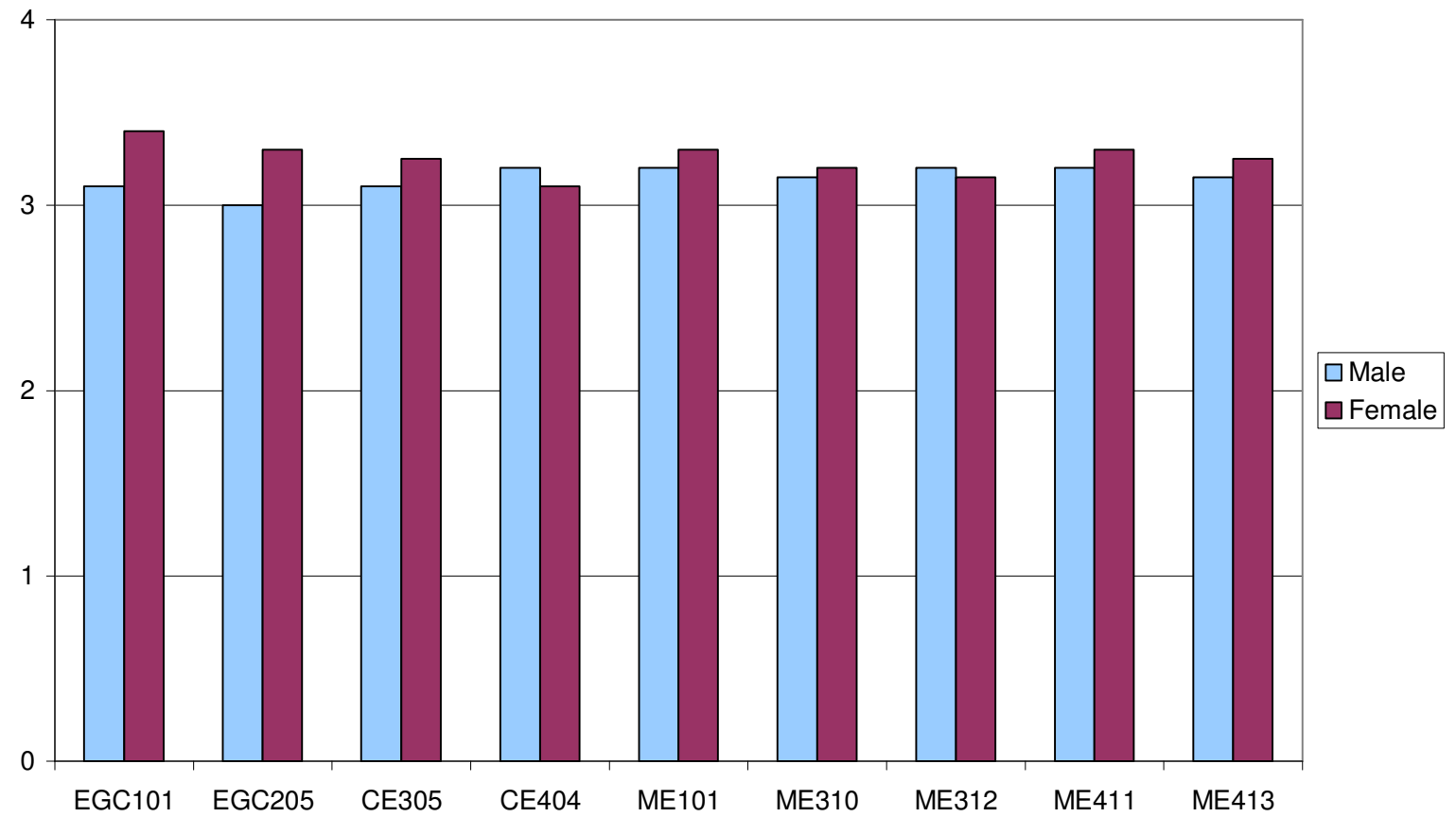

Fig. 2. Average Grade Points for Male and Female students in different Civil and Mechanical Engineering courses. 


\section{Causes of Low Enrollment of Female Engineers}

After finding that the minority female students are equally capable to study engineering, yet had very poor representation, the next step was to explore the probable causes. Hence, a survey tool was developed with possible causes for low enrollment of women in engineering, particularly minority black women, and shown in Table 2. The survey tool was circulated among the female students of both the Civil Engineering and Mechanical Engineering departments of AAMU. The students were asked to rate their responses on a scale of $1-4$. The student responses were compiled, averaged and presented in Fig. 3.

Table 2. Survey Tool for possible causes of low Enrollment of Women in Engineering.

\begin{tabular}{|c|c|c|c|c|}
\hline \multicolumn{7}{|c|}{ Civil / Mechanical Engineering Department, AAMU } \\
\multicolumn{5}{|c|}{ Survey Tool for causes of low Enrollment of Women in Engineering } \\
In a scale of 1 to 4 (1 - minimum, 4 - maximum), rate the following items you believe might \\
be possible causes for low enrollment of women in engineering: \\
\hline $\begin{array}{c}\text { Item } \\
\#\end{array}$
\end{tabular}




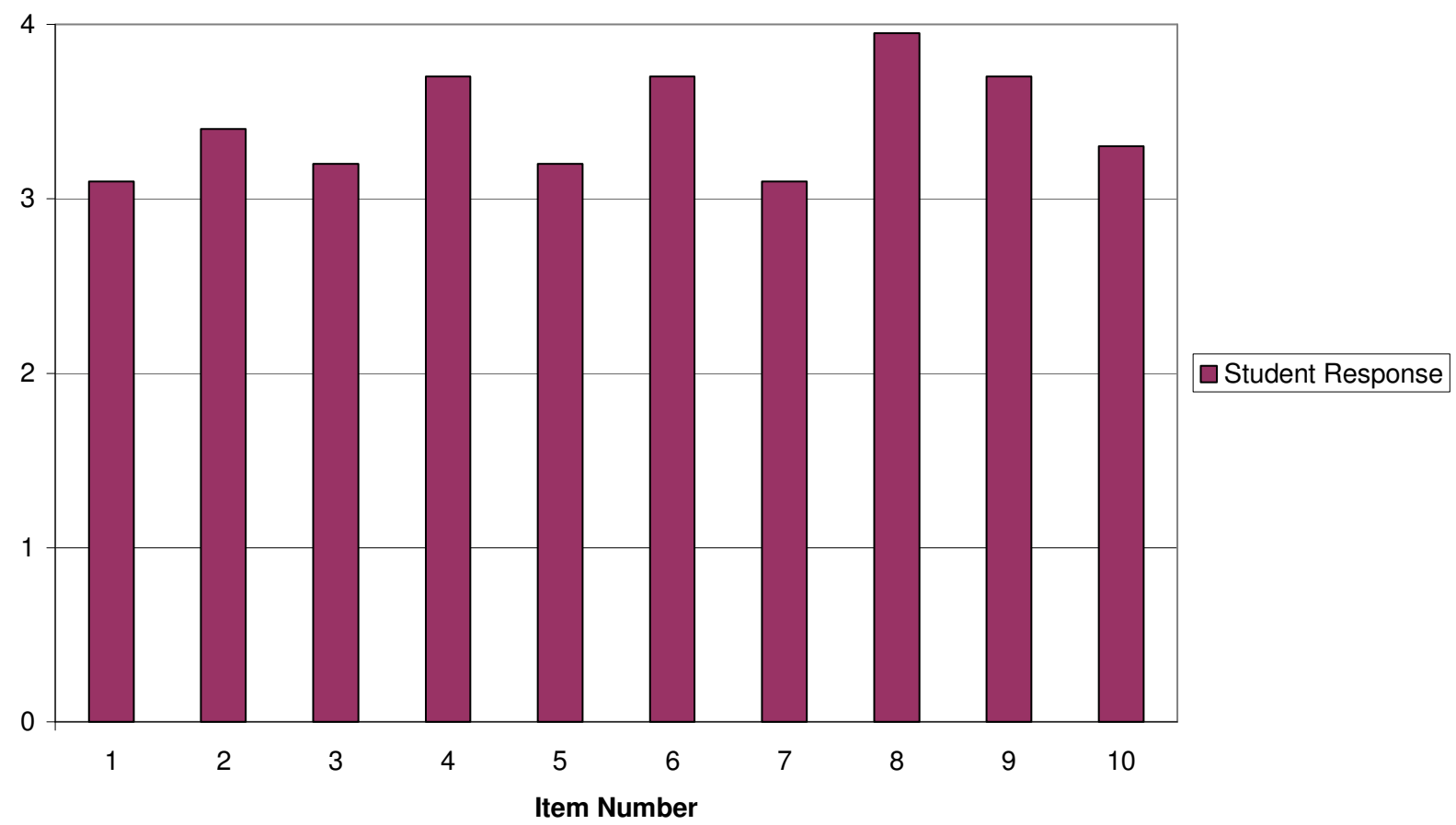

Fig. 3. Response of students about the items that might be possible causes for low enrollment of women in engineering.

From Fig. 3, it is observed that almost all of the students strongly agree that minority black women have a general tendency to study Liberal Arts or Humanities subjects. In addition, most of the students agree that lack of proper Math and Science courses in high school, lack of motivation or influence from family to study engineering, ignorance of engineering workenvironment and job pattern (not always field work), misconception about engineering - not suitable for women, and economic condition are some of the major factors that affect the enrollment of minority women in engineering.

\section{Solutions to increase Enrollment of Female Engineers}

For finding the probable solution to this problem a survey tool was also developed with some suggestions or ideas, and presented in Table 3. The survey was again conducted among the female students of both the Civil Engineering and Mechanical Engineering departments of AAMU. The survey results were processed and presented in Fig. 4.

In Fig. 4, it is found that all the students strongly agree that more scholarships for freshmen and sophomore female students, and more Summer Internship opportunities for women are needed to increase the enrollment of women in engineering. Most of the students also agree that through giving proper idea about engineering work environment and job pattern, increasing awareness about job prospect and benefit for engineering jobs among high school students, encouraging female students at high school to take math and science courses to prepare for 
engineering, communicating with families to encourage female students to study engineering for better prospect, and "Engineering for all - Male and Female" conveying this message to high school and freshmen students would increase the enrollment of minority women in engineering.

Table 3. Survey Tool for possible solutions to increase Enrollment of Women in Engineering.

\begin{tabular}{|c|c|c|c|c|}
\hline \multicolumn{7}{|c|}{ Civil / Mechanical Engineering Department, AAMU } \\
Survey Tool to increase Enrollment of Women in Engineering \\
In a scale of 1 to 4 (1 - minimum, 4 - maximum), rate the following items that you believe \\
might help to increase the enrollment of women in engineering: \\
\hline $\begin{array}{c}\text { Item } \\
\#\end{array}$
\end{tabular}




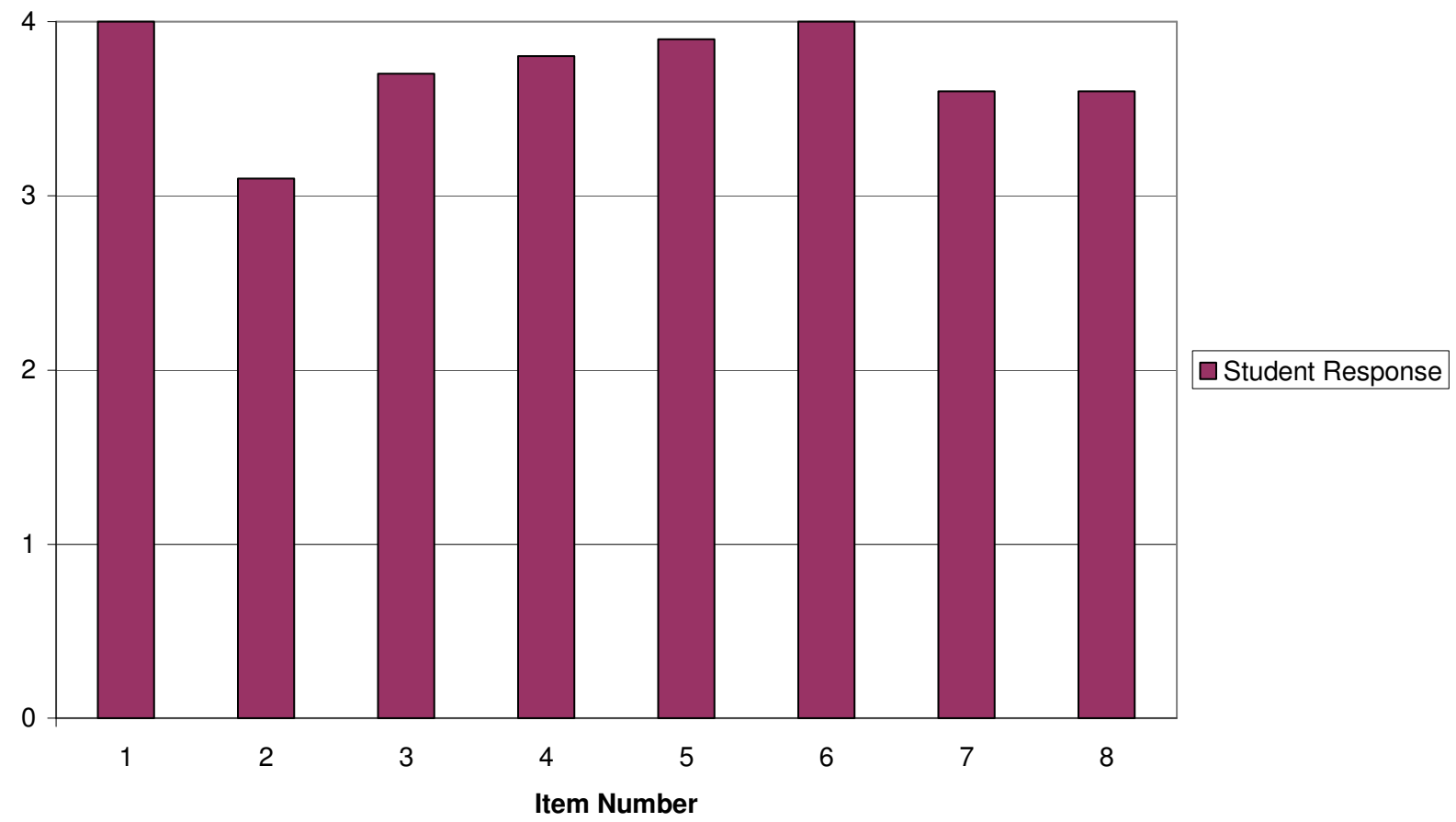

Fig. 4. Response of students about the items that might increase enrollment of women in engineering.

\section{Conclusion}

This paper shows that the enrollment of minority black women in engineering is alarmingly low. The female students are capable to study engineering along with their male counterpart. In fact, their performance is sometimes slightly better. But unfortunately they have a general tendency to study Liberal Arts or Humanities subjects due to lack of motivation from family, lack of proper courses in high school, misconception about engineering, and economic reasons. By arranging more scholarships and summer internships for female students, encouraging high school students and families, and increasing awareness about engineering job, the enrollment of minority African American Women in engineering can be significantly increased. This will lead to a balanced workforce and improve the national economy.

\section{Bibliography}

1. Engineering Criteria 2000, Third Edition, Engineering Accreditation Commission of the Accreditation Board for Engineering and Technology, December 1997.

2. Strategies for Success: Enhancing Minority Student Success in Science, Engineering and Technology Professions, Patricia Tolley, Catherine Blat, Deborah Sharer, Farid Tranjan, University of North Carolina, Charlotte, ASEE Paper, Session 3470, 2004 ASEE Annual Conference and Exposition, Salt Lake City, Utah. 
3. Effect of Personal Contact in Improving the Outcome of Minority Engineering Students, Showkat J. Chowdhury, Ruben Rojas-Oviedo, Mechanical Engineering Department, Alabama A\&M University, ASEE Paper, Session 1566, 2004 ASEE Annual Conference and Exposition, Salt Lake City, Utah.

4. The North Carolina State University Women in Science and Engineering Program: A Community for Living and Learning, S.A. Rajala, L.J. Bottomley, E.A. Parry, J.D. Cohen, S.C. Grant, C.J. Thomas, T.M. Doxey, G. Perez, R.E. Collins, and J.E. Spurlin, North Carolina State University, ASEE Paper, Session 3192, 2004 ASEE Annual Conference and Exposition, Salt Lake City, Utah.

5. Assessing Women in Engineering (AWE): Assessment results on Women Engineering Student Beliefs, Rose M. Marra, Cherith Moore, Mieke Schuurman, Barbara Bogue, University of Missouri - Columbia / Pennsylvania State Universty, ASEE Paper, Session 1392, 2004 ASEE Annual Conference and Exposition, Salt Lake City, Utah 